\title{
38-Year-Old Captain Suffers a Heart Attack at a Medical Call and Dies 4 Days Later-Nebraska
}

\section{Executive Summary}

On June 23, 2016, a 38-year-old male volunteer captain responded to an emergency medical call. While helping transfer a patient from a car onto a stretcher, he started to feel as though "someone had dropped the car" on his chest. After the ambulance left with the patient, the Captain drove a private vehicle to the fire station, then drove to his parents' home. His chest pain continued and his mother drove him to the hospital emergency department, where testing showed he was having a heart attack. In the coronary catheterization laboratory (“cath lab”), a stent placed a year earlier was found to be blocked. A balloon was inserted to open the blockage, blood flow was restored, and the Captain's chest pain resolved. Because of a decline in his heart's pumping function and a history of multiple stents, coronary artery bypass graft (CABG) surgery was offered. CABG uses healthy vessels from other parts of the body to bypass blocked arteries in the heart. Before he could undergo surgery, the Captain suffered cardiac arrest and died despite multiple rounds of cardiopulmonary resuscitation (CPR) and advanced life support (ALS) measures.

The death certificate was completed by the attending physician. The cause of death was listed as "cardiac arrhythmia” due to "coronary artery disease” due to "diabetes.” No autopsy was performed. NIOSH investigators concluded that the physical exertion of loading a patient may have exacerbated the Captain's underlying coronary artery disease and triggered a heart attack (myocardial infarction).

The Captain had multiple risk factors for coronary artery disease, including long-standing diabetes, smoking, high blood pressure, dyslipidemia, and family history of early heart disease. He suffered his first heart attack at age 30 and subsequently underwent multiple hospitalizations and interventions for severe disease.

\section{Key Recommendations}

- Provide preplacement and annual medical evaluations to all fire fighters consistent with National Fire Protection Association (NFPA) 1582, Standard on Comprehensive Occupational Medical Program for Fire Departments, to identify fire fighters at increased risk for sudden cardiac events.

- Ensure that fire fighters are cleared for duty by a physician knowledgeable about the physical and mental demands of fire fighting, the personal protective equipment used, and other guidance in NFPA 1582.

NIOSH investigators include the following recommendations to address general safety and health issues: 


\section{8-Year-Old Captain Suffers a Heart Attack at a Medical Call and Dies 4 Days Later-Nebraska}

- Perform an annual physical ability test (physical performance evaluation).

- Phase in a mandatory wellness and fitness program to benefit all fire fighters.

- Provide fire fighters with medical clearance to wear a self-contained breathing apparatus (SCBA) as part of the fire department's medical evaluation program.

The National Institute for Occupational Safety and Health (NIOSH), an institute within the Centers for Disease Control and Prevention (CDC), is the federal agency responsible for conducting research and making recommendations for the prevention of work-related injury and illness. In 1998, Congress appropriated funds to NIOSH to conduct a fire fighter initiative that resulted in the NIOSH Fire Fighter Fatality Investigation and Prevention Program, which examines line-of-duty deaths or on-duty deaths of fire fighters to assist fire departments, fire fighters, the fire service, and others to prevent similar fire fighter deaths in the future. The agency does not enforce compliance with state or federal occupational safety and health standards and does not determine fault or assign blame. Participation of fire departments and individuals in NIOSH investigations is voluntary. Under its program, NIOSH investigators interview persons with knowledge of the incident who agree to be interviewed and review available records to develop a description of the conditions and circumstances leading to the death(s). Interviewees are not asked to sign sworn statements and interviews are not recorded. The agency's reports do not name the victim, the fire department or those interviewed. The NIOSH report's summary of the conditions and circumstances surrounding the fatality is intended to provide context to the agency's recommendations and is not intended to be definitive for purposes of determining any claim or benefit.

For further information, visit the program website at www.cdc.gov/niosh/fire or call toll free 1-800-CDC-INFO (1-800-232-4636). 


\section{8-Year-Old Captain Suffers a Heart Attack at a Medical Call and Dies 4 Days Later-Nebraska}

\section{Introduction}

On June 27, 2016, a 38-year old volunteer captain died after suffering a heart attack at a medical call 4 days earlier. NIOSH was notified of this fatality on June 29, 2016, by the U.S. Fire Administration. NIOSH contacted the affected fire department on July 22, 2016, to gather additional information and on July 27, 2016, to initiate the investigation. On August 23, 2016, a safety and occupational health specialist from the NIOSH Fire Fighter Fatality Prevention and Investigation Program conducted an on-site investigation of the incident.

During the investigation, NIOSH personnel interviewed the following people:

- Fire Chief

- Captain’s spouse

NIOSH personnel reviewed the following documents:

- Fire department standard operating guidelines

- Witness statement

- Emergency department (ED) report

- Outpatient medical records

- Hospital records

- Death certificate

\section{Investigation}

On June 23, 2016, the Captain, who was also an emergency medical technician (EMT), was dispatched to an emergency medical call at 1845 hours. He and his wife, also a fire department member, responded in their privately owned vehicle. They arrived at the scene at 1849 hours behind the ambulance. The Captain assisted with patient care. While helping transfer the patient from a car onto a stretcher, the Captain suddenly felt as though "someone had dropped the car" on his chest. The patient was transported to the hospital in an ambulance, and the Captain's wife rode with the patient. The Captain drove another member's vehicle to the fire station. He left the fire station and drove to his parents' home. His chest pain continued, and his mother drove him to the ED.

The Captain walked into the ED at 1932 hours complaining of continuous chest pain since loading a patient about an hour earlier. The pain and pressure were located in his left chest and radiated to his jaw, neck, and shoulder. He was sweating and had nausea, a headache, and some shortness of breath. He also revealed a history of exertional chest pain over the past few days that had been relieved with rest. Testing confirmed he was having an acute non-ST wave elevation myocardial infarction, based on an EKG (electrocardiogram) and elevated level of troponin-I, a biomarker for myocardial damage. He had taken a nitroglycerin tablet (vasodilator) prior to arrival, and in the ED received four baby aspirin to slow clotting. After receiving intravenous (IV) nitroglycerin, heparin (blood thinner), and morphine, his chest pain improved. Testing revealed acute kidney injury in addition to his underlying diabetic nephropathy, and he received IV fluid therapy to support his kidney function.

The next day (June 24, 2016), laboratory testing indicated his troponin-I level was declining, and his kidney function was slightly improved. An echocardiogram revealed the function of his left ventricle 


\section{8-Year-Old Captain Suffers a Heart Attack at a Medical Call and Dies 4 Days Later-Nebraska}

was mildly depressed. The ejection fraction had declined to $40 \%-45 \%$ (compared to $>55 \%$ in 2013 ; normal is 50\%-70\% [AHA 2015; Lang et al. 2015]), and the inferior-lateral area showed weakened contraction. He was taken to the cath lab where he underwent coronary angiography (injection of dye to identify blockages). His left anterior descending artery was partially occluded (25\%-75\%) in multiple areas of the vessel, and a previously placed stent in his left circumflex artery had become completely blocked (restenosis). Angioplasty was performed, blood flow improved, and his pain completely resolved. No new stents were inserted. His right coronary artery (nondominant) was not explored to spare renal injury from the contrast dye. This artery was already known to be 100\% occluded, but collateral circulation had developed to reroute blood around the blockage.

Because of the Captain's history of reduced ventricular function and multiple stents, CABG surgery was scheduled to take place in few days. However, on June 25, 2016, the Captain developed acute respiratory failure. He was placed on a nonrebreather mask for greater oxygen delivery and received a bronchodilator breathing treatment. A chest x-ray showed fluid in his lungs (pulmonary edema), and a diuretic was given to help remove the fluid. His condition improved and he remained on oxygen. On June 26, 2016, telemetry monitoring showed his heart was beating slightly faster than normal (about 105 beats per minute; normal is 60-100). Overnight he experienced some chest pain, but this was thought to be due to anxiety.

On the morning of June 27, 2016, his condition deteriorated. His blood pressure dropped, his heart rate increased to the 120s (sinus tachycardia), and he developed shortness of breath. A chest x-ray showed increased fluid and possible pneumonia. His IV medications were adjusted, oxygen delivery was increased, and IV antibiotics and blood cultures were ordered. An EKG showed a problem with electrical conduction in his heart (left bundle branch block). An echocardiogram revealed his left ventricular function had deteriorated from 2 days earlier, with an ejection fraction of only 25\%-30\% and weakened contraction noted throughout. He was transferred to the intensive care unit. En route, he developed pulseless electrical activity (PEA) and suffered cardiac arrest. CPR and ALS were begun. He had spontaneous return of his circulation several times and brief episodes of ventricular tachycardia, for which he was shocked twice. However, each time he reverted to PEA and cardiac arrest. After more than 60 minutes of multiple cycles of CPR and ALS, resuscitation efforts were discontinued. The intensive care unit physician pronounced the Captain dead.

\section{Medical Findings}

The death certificate was completed by the attending physician. The cause of death was listed as “cardiac arrhythmia” due to “coronary artery disease” due to “diabetes.” No autopsy was performed.

The Captain had a complicated medical history as described below. In review of all available records for encounters between 2006 and 2016, however, no reference to his being a fire fighter was found apart from a primary care physician (PCP) note that mentioned he was in paramedic school and the ED note that referenced his EMT duties.

\section{Coronary Artery Disease}




\section{8-Year-Old Captain Suffers a Heart Attack at a Medical Call and Dies 4 Days Later-Nebraska}

The Captain was first diagnosed with coronary artery disease at age 30 in 2007, when he suffered an ST-elevation myocardial infarction of the anterior wall and was found to have severe disease involving the three main coronary arteries. Over the next 9 years he was hospitalized approximately 10 times for chest pain (angina), received at least eight cardiac catheterizations, six stents, and several balloon angioplasties. He was treated with multiple medications, including therapies to prevent clotting in his stents and arteries, lower the risk of subsequent myocardial infarction, reduce ischemia, lower lipids, and reduce his urge to smoke.

After his heart attack in 2007, the Captain underwent treadmill stress testing with nuclear perfusion imaging. The test was terminated early due to ankle pain from a prior injury. No ischemia or arrhythmias were noted for the workload he achieved (7.9 METs [metabolic equivalents]; 63\% maximum predicted heart rate). The Captain's work as a fire fighter was not mentioned, and no work restrictions were documented.

In January 2016, the Captain experienced abdominal pain, and surgeons recommended removal of his gallbladder. A pre-operative cardiology consultation assessed his risk for cardiac events during/after surgery to be "acceptable" on the basis of preserved systolic function, no current angina, and "no limitation in performing daily duties and achieving activity level above 5 METs.” Approximately 2 weeks post-op, the surgeon cleared the Captain to return to work (his fire fighter duties were not mentioned), but advised against heavy lifting for 2 more weeks because his diabetes slowed wound healing.

\section{Type 1 Diabetes Mellitus}

The Captain was diagnosed with type 1 (insulin-requiring) diabetes at 3 years of age. His diabetes was not well controlled. He had microvascular complications, with early nephropathy (proteinuria) and retinopathy (treated with laser therapy) since at least 2006. Between 2006 and mid-2010 his glycosylated hemoglobin (A1C), which reflects diabetes control over the past 2-3 months, ranged from $7.9 \%$ to $11.1 \%$, which reflects estimated average blood glucose of 180 to $272 \mathrm{mg} / \mathrm{dL}$ (milligrams per deciliter). The diabetes treatment goal is A1C $<7 \%$, which corresponds to an average blood glucose of 154 mg/dL [ADA no date; ADA 2017; Nathan et al. 2008]. In 2010, he received an insulin pump. His A1C levels improved somewhat, ranging from 7.3\% to 10.1\% (estimated average glucose of 163 to $209 \mathrm{mg} / \mathrm{dL}$ ). However, he also had more frequent low glucose readings. Although he denied hypoglycemic symptoms, his diabetes physician was concerned and recommended no climbing on ladders at his construction job (2012).

\section{Dyslipidemia}

The Captain had dyslipidemia (unhealthy cholesterol levels) since at least 2006. His baseline values were not available, but notes from his diabetes physician indicated his bad cholesterol (low density lipoprotein or LDL) was too high, and his good cholesterol (high density lipoprotein or HDL) was too low. After starting a statin medication and niacin, his LDL was noted to improve, but his low HDL persisted. His most recent lipid profile (2013) showed a desirable level of LDL (69 mg/dL; optimal $<100$ ) and low HDLs (25 mg/dL; normal >40) [NHLBI 2005]. 


\section{8-Year-Old Captain Suffers a Heart Attack at a Medical Call and Dies 4 Days Later-Nebraska}

\section{Stage I Hypertension}

The Captain had hypertension since at least 2006, with blood pressure of 140/84-90 mm Hg (millimeters of mercury); normal is $<120 / 80$. Stage I is 140-149/90-99 mm Hg [NHLBI 2015].

Treatment with an ACE inhibitor (angiotensin converting enzyme) and beta-blocker improved its control. His most recent readings from March-June 2016 were in the normal to Stage I range (110/80 to $150 / 90 \mathrm{~mm} \mathrm{Hg})$.

\section{$\underline{\text { Asthma }}$}

He was diagnosed with asthma in childhood, but as an adult only required treatment with an albuterol inhaler as needed. His last hospitalization for asthma was remote (2001).

\section{Smoking}

The Captain began smoking in his later teens. He averaged about one pack per day between 2006 and 2015, with several periods of cutting down or stopping. He was prescribed medication to counteract the urge to smoke and quit smoking on January 1, 2016.

\section{Anxiety and Depression}

These conditions were diagnosed around 2006 and treated with an antidepressant.

\section{Fire Department}

At the time of the NIOSH investigation, the volunteer fire department consisted of two fire stations with a total of 23 uniformed personnel. It served 7,000 residents in a geographic area of 275 square miles.

\section{Membership, Training, and Experience}

New fire fighter applicants are required to have a state driver's license and pass a background check. The applicant must list any disability or handicap on the application, which determines whether he/she can become an interior structural fire fighter, external support fire fighter, or a nonemergency response member. New members are on probation for 6 months. They receive in-house basic fire fighter training. The fire department offers training twice monthly. The state of Nebraska does not have minimum training standards.

The Captain was certified as a Fire Fighter I and an EMT. He was promoted to Captain in 2015 and had 16 years of experience as a fire fighter. Because of his medical conditions, the Captain restricted himself from interior structural fire fighting. He primarily performed EMT duties, but occasionally participated in exterior fire suppression and driver/operator duties.

\section{Medical Evaluations and Return to Work Evaluations}




\section{8-Year-Old Captain Suffers a Heart Attack at a Medical Call and Dies 4 Days Later-Nebraska}

The fire department does not require preplacement or periodic medical evaluations. If a member is injured on duty, clearance for return to duty is required. Clearance is provided by the member's PCP, and the Fire Chief makes the final determination regarding return to duty. If a member has a major illness and cannot respond to emergencies or participate in other department activities, the member's PCP must provide medical clearance. The Fire Chief makes the final decision about return to duty.

\section{Wellness-Fitness Programs and Physical Ability Evaluations}

The fire department does not require candidate or annual physical ability evaluations. The department does not have a wellness-fitness program. The Captain exercised at least 3 times per week by walking for about 30 minutes and lifting weights.

\section{Discussion}

\section{Coronary Artery Disease and Sudden Cardiac Events}

Atherosclerotic coronary artery disease is a chronic inflammatory disease that causes hardening and narrowing of arteries and build-up of plaque in the walls. Onset begins in childhood [Hong 2010]. By age 10, about half of children in the United States have fatty streaks in their coronaries [Stary 1989].

Atherosclerotic plaque consists of a lipid core covered by a fibrous cap. Plaque is thought to grow in fits and starts instead of accumulating in a steady manner [Libby 2002, p. 53]. If the cap on the plaque is thin or unstable it can break open [Libby 2015]. This sets off a coagulation cascade to repair the damage, which can result in formation of a thrombus (blood clot) on top of the plaque. If the thrombus causes sudden blockage of a main coronary, a heart attack can occur. If an artery is only partially blocked, a person can experience angina from restricted blood flow but not progress to a heart attack.

A heart attack is defined as myocardial cell death due to prolonged ischemia from lack of blood flow (the heart muscle is essentially starved for oxygen) [Thygesen et al. 2012]. An acute or recent heart attack can be confirmed by characteristic changes on an EKG, an elevated blood level of cardiac biomarker/enzymes, or evidence of a thrombus (clot) [Jneid et al. 2013].

Atherosclerotic coronary artery disease (coronary heart disease) is responsible for most (>80\%) sudden cardiac deaths in the United States [Myerburg and Castellanos 2015]. This is also the case among fire fighters, with approximately $90 \%$ of sudden cardiac deaths attributable to coronary artery disease [Yang et al. 2013].

Major risk factors for coronary artery disease and heart attacks are well known. Fixed risk factors include male sex, age $>45$ years, and heredity/family history. Most risk factors can be controlled or eliminated by lifestyle changes or medications, such as smoking, hypertension, diabetes, dyslipidemia, obesity, and lack of physical inactivity [AHA 2016a; NHLBI 2016]. The Captain had two fixed risk factors (male sex and family history of premature heart disease), and four modifiable ones (smoking, high blood pressure, dyslipidemia, diabetes).

\section{Left Ventricular Hypertrophy}




\section{8-Year-Old Captain Suffers a Heart Attack at a Medical Call and Dies 4 Days Later-Nebraska}

Left ventricular hypertrophy $(\mathrm{LVH})$ is heart damage from long-standing hypertension. The Captain had elevated blood pressure for at least 10 years. Hypertension makes the heart work harder, which over time can cause the muscle to thicken or hypertrophy [Lip et al. 2017; Siegel 1997; Tin et al. 2002]. $\mathrm{LVH}$ is a concern for sudden incapacitation, as it is known to increase the risk of arrhythmia and sudden cardiac death [Levy et al. 1990; Tin et al. 2002]. Several of the Captain's echocardiograms showed mild concentric LVH, with a posterior wall thickness of 1.1 to $1.3 \mathrm{~cm}$ (centimeters); normal range for men is 0.6 to $1.1 \mathrm{~cm}$ [Lang et al. 2015].

\section{Physiological Stress and Fire Fighter Duties}

Heart attacks and sudden cardiac death can be triggered by strenuous physical exertion, and the risk is higher among persons who are sedentary or exercise infrequently [Albert et al. 2000; Mittleman and Siscovick 1996; Willich et al. 1993]. Among fire fighters, activities that can trigger sudden cardiac events include fire suppression, responding to an alarm, returning from an alarm, and physically demanding training, such as live fire drills, search and rescue, or physical fitness training [Kales et al. 2003, 2007; NIOSH 2007]. Fire fighters with underlying risk factors for cardiovascular disease are much more susceptible to triggers, including fire fighters who smoke, have high blood pressure, are older ( $>45$ years), or have evidence of underlying arterial occlusive disease (such as history of angina, angioplasty, heart attack, or carotid stenosis) [Kales et al. 2003].

On June 23, 2016, the Captain responded to an emergency medical call. He provided medical care on the scene and had sudden onset of angina while helping load a patient onto a stretcher. The estimated workload for these tasks is approximately 3-5 METs, which is considered a moderate level of physical activity and could have triggered his heart attack [Ainsworth et al. 2011; Gledhill and Jamnik 1992].

\section{Occupational Medical Standards for Structural Fire Fighters}

To ensure a fire fighter is capable of performing required duties and reduce the risk of conditions posing a safety hazard to the fire fighter and others, the National Fire Protection Association developed NFPA 1582, Standard on Comprehensive Occupational Medical Program for Fire Departments [NFPA 2013a]. This is a voluntary industry standard developed through consensus. It outlines the physical exam, medical history, and ancillary tests recommended for preplacement and annual evaluations, and provides guidance for determining medical fitness for duty. It also describes roles and responsibilities for the fire department, physician, and fire fighter, among other components.

The Captain had several conditions and medications that are addressed by NFPA 1582 regarding medical fitness for duty:

- Coronary artery disease

- Type 1 diabetes mellitus

- Stage I hypertension

- Beta-blocker medication use

- Anticoagulant medication use

- Asthma 


\section{8-Year-Old Captain Suffers a Heart Attack at a Medical Call and Dies 4 Days Later-Nebraska}

According to NFPA 1582, the Captain's medical issues should have resulted in duty limitations, as explained below.

\section{Coronary Artery Disease}

NFPA 1582 states that a history of myocardial infarction, coronary artery bypass surgery, coronary angioplasty with stent placement, or similar procedures compromise the fire fighter's ability to safely perform a number of essential tasks for alarm response. For example, history of a heart attack could impair a fire fighter's ability to safely rescue and carry adult victims while wearing the full personal protective ensemble/SCBA, or compromise the ability to function as an integral member of a team, where sudden incapacitation could jeopardize the mission or place other team members or civilians at risk of injury or death [NFPA 2013a].

The standard recommends the physician report duty limitations to the fire department if the fire fighter has any of the following:

- Current angina pectoris (chest pain) even if relieved by medication

- Persistent significant stenosis in any coronary artery (>70\%) following treatment

- Lower than normal left ventricular ejection fraction as measured by echocardiography, radionuclide scan, or contrast ventriculography.

- Maximal exercise tolerance of less than 12 METs

- Exercise-induced ischemia or ventricular arrhythmias observed by radionuclide stress test during an evaluation reaching a workload of at least 12 METs

- History of myocardial infarction, angina, or coronary artery disease with persistence of modifiable risk factor(s) for acute coronary plaque rupture (e.g., tobacco use, hypertension despite treatment, hypercholesterolemia with total cholesterol $\geq 180$ or LDL $\geq 100$ despite treatment, or glycosylated hemoglobin A1C $>7 \%$ despite exercise and/or weight reduction) [NFPA 2013a].

The Captain's coronary artery disease was diagnosed when he suffered his first heart attack in 2007. He had severe coronary artery stenosis/restenosis, recurrent episodes of angina, did not achieve 12 METs on an exercise stress test, and had persistent modifiable risk factors for acute plaque rupture, to include smoking and elevated A1C levels. Therefore, NFPA 1582 guidance would have recommended duty limitations.

\section{Diabetes Mellitus}

NFPA 1582 provides guidance for the physician to assess a fire fighter with diabetes. It notes that diabetes that requires treatment with insulin compromises a fire fighter's ability to safely perform a number of essential tasks including emergency response involving prolonged periods of extreme physical exertion without the benefit of warm-up, scheduled rest breaks, meals, access to medications, or hydration [NFPA 2013a].

The standard recommends the physician report duty limitations to the fire department unless the fire fighter meets all of the following criteria:

(1) Is maintained by a physician knowledgeable in current management of diabetes mellitus 


\section{8-Year-Old Captain Suffers a Heart Attack at a Medical Call and Dies 4 Days Later-Nebraska}

(2) Has demonstrated over a period of at least 6 months the motivation and understanding required to closely monitor and control capillary blood glucose levels through nutritional therapy and insulin administration

(3) Has a dilated retinal exam by a qualified ophthalmologist or optometrist that shows no higher grade of diabetic retinopathy than microaneurysms

(4) Has normal renal function on the basis of a calculated creatinine clearance greater than 60 milliliters per minute and absence of proteinuria

(5) Has no autonomic or peripheral neuropathy

(6) Has normal cardiac function without evidence of myocardial ischemia on cardiac stress testing (to at least 12 METs) by EKG and cardiac imaging

(7) Has a signed statement and medical records from an endocrinologist or a physician with demonstrated knowledge in the current management of diabetes mellitus as well as knowledge of the essential job tasks and hazards of fire fighting, allowing the fire department physician to determine whether the member meets the following criteria:

(a) Is maintained on a stable insulin regimen and has demonstrated over a period of at least 6 months the motivation and understanding required to closely monitor and control capillary blood glucose levels despite varied activity schedules through nutritional therapy and insulin administration

(b) Has had glycosylated hemoglobin A1C measured at least 4 times a year (intervals of 2 to 3 months) over the last 12 months prior to evaluation, if the diagnosis of diabetes has been present over 1 year. A hemoglobin A1C reading of $\geq 8 \%$ shall trigger a medical evaluation to determine if a condition exists in addition to diabetes that is responsible for the $\mathrm{A} 1 \mathrm{C}$ not accurately reflecting average glucose levels.

(c) Does not have an increased risk of hypoglycemia due to alcohol use or other predisposing factors

(d) Has had no episodes of severe hypoglycemia (defined as requiring assistance of another) in the preceding 12 months, with no more than two episodes of severe hypoglycemia in the preceding 3 years

(e) Is certified not to have a medical contraindication to fire fighting training and operations [NFPA 2013a].

The Captain's type 1 diabetes was not well controlled and he had evidence of diabetes-related microvascular and macrovascular disease. Because he did not meet all of the above criteria, NFPA 1582 would have recommended duty limitations.

\section{Hypertension}

For a fire fighter such as the Captain with stage I hypertension, NFPA 1582 recommends PCP referral to ensure blood pressure is well controlled, to address lifestyle modifications, and to determine if screening for asymptomatic end organ damage is warranted, for example, retinopathy, nephropathy, $\mathrm{LVH}$, or vascular complications. Hypertension with end organ damage could impair a fire fighter's ability to perform emergency response actions while in full gear/SCBA under stressful conditions, 


\section{8-Year-Old Captain Suffers a Heart Attack at a Medical Call and Dies 4 Days Later-Nebraska}

including operating in extreme environments for long durations [NFPA 2013a]. The Captain was already known to have developed $\mathrm{LVH}$, a common consequence of chronic hypertension that is associated with sudden cardiac death.

\section{Beta-Blocker Medication}

Beta-blockers compromise the fire fighter's ability to perform tasks requiring wear of encapsulating protective gear because of the risk for dehydration, electrolyte abnormalities, and lethargy. The Captain was placed on a beta-blocker after his heart attack in 2007. NFPA 1582 would have recommended physician evaluation for consideration of job limitations.

\section{Anticoagulant Medication}

Anticoagulants increase the propensity for internal bleeding, which is a concern for duties involving a fall risk such as climbing ladders or operating from heights. The Captain was taking two antiplatelet medications. NFPA 1582 would have recommended physician evaluation to advise on applicable job limitations.

\section{Asthma}

Asthma may compromise the fire fighter's ability to safely perform essential tasks such as climbing multiple flights of stairs in protective gear/SCBA and carrying equipment. Fire fighting also requires the ability to tolerate the increased respiratory workload of an SCBA or HEPA filter mask. Fire fighters may be exposed to irritants, particulates, or other potential asthma triggers despite the use of personal protective equipment and SCBA, and may have to function for prolonged periods without access to medications and scheduled rest periods.

The Captain had a history of asthma, for which he used a bronchodilator inhaler as needed. He had not been hospitalized for asthma in 15 years. While it appears from available records that his asthma was mild, NFPA 1582 would have recommended physician evaluation to assess his pulmonary status, work history, and the need for any duty limitations.

\section{Summary}

The information available to the NIOSH investigators indicates the Captain did not meet NFPA 1582 medical criteria for unrestricted fire fighting duties. While his self-imposed duty limitations (no interior structural fire fighting) excluded him from some of the most demanding fire fighter duties, his severe coronary artery disease included episodes of angina that occurred without any exertional trigger. The self-imposed restrictions were not sufficient to meet 1582 recommendations.

\section{Recommendations}

Recommendation \#1: Provide preplacement and annual medical evaluations to all fire fighters consistent with National Fire Protection Association (NFPA) 1582, Standard on Comprehensive Occupational Medical Program for Fire Departments, to identify fire fighters at increased risk for sudden cardiac events. 


\section{8-Year-Old Captain Suffers a Heart Attack at a Medical Call and Dies 4 Days Later-Nebraska}

Discussion: Although not legally required to follow NFPA 1582, candidate and annual evaluations are highly encouraged and the fire department should make efforts to ensure fire fighters can perform duties without undue risk of harm to self or others. The National Volunteer Fire Council (NVFC) and the International Association of Fire Chiefs (IAFC) both endorse annual evaluations for all fire fighters [IAFC 2016; NVFC 2016].

Recognizing that many departments struggle to identify adequate resources to provide comprehensive evaluations, fire service and medical experts developed a guide to assist community physicians and others to provide occupational exams to fire fighters. The Healthcare Provider's Guide to Firefighter Physicals [IAFC 2016] includes a checklist of exam components for fire fighter physicals, as well as background on the physiological demands and other unique health risks that fire fighters face. This free guide can be downloaded from the International Association of Fire Chiefs’ website.

The fire department does not offer candidate or periodic fire fighter medical exams. The Captain received care for his medical issues from several private physicians. From record review, it appears that a number of exam components recommended by NFPA 1582 were provided during these visits. However, it is not clear if his personal physicians were aware of his fire fighter duties or the guidance in NFPA 1582.

Recommendation \#2: Ensure that fire fighters are cleared for duty by a physician knowledgeable about the physical and mental demands of fire fighting, the personal protective equipment used, and other guidance in NFPA 1582.

Discussion: The fire department has a process for medical clearance/return to duty. Following an onduty injury or major illness, the fire fighter's PCP is to provide clearance or recommend duty limitations, with the Fire Chief making the final determination. From record review, it is not known if the Captain's physicians were aware of his fire fighter duties and related NFPA 1582 guidance. Only a few physician notes addressed medical clearance or duty limitations, and these were general in nature.

It would be advisable for the fire department to review its current process to ensure it would prevent a fire fighter with a significant injury/illness from returning to duty without medical evaluation. The department should also ensure physicians are aware of essential fire fighter tasks, the physical demands and required PPE, and the risks posed by incapacitating conditions such as sudden cardiac events or severe hypoglycemia. A new tool to aid fire fighters and their treating physicians is the Healthcare Provider's Guide to Firefighter Physicals [IAFC 2016]. Resources for fire departments on comprehensive occupational medical programs include NFPA 1582 [NFPA 2013a] and A Fire Department's Guide to Implementing NFPA 1582 [IAFC 2013].

NIOSH investigators include the following recommendations to address general safety and health issues:

Recommendation \#3: Perform an annual physical ability test (physical performance evaluation). 


\section{8-Year-Old Captain Suffers a Heart Attack at a Medical Call and Dies 4 Days Later-Nebraska}

Discussion: According to Chapter 10 in NFPA 1500, Standard on Fire Department Occupational Safety and Health Program, the fire department should set physical ability requirements for fire fighters who engage in emergency operations to ensure they are physically capable of carrying out essential job tasks for structural fire fighting [NFPA 2013b]. Candidates should be qualified prior to entering into fire fighter training, and fire fighters who are involved in emergency operations should be evaluated and certified annually. Fire fighters unable to meet the requirements should not participate in emergency operations and should enter a rehabilitation program.

The fire department does not require candidate or annual physical ability evaluations. A physical ability evaluation could be accomplished as part of the department's monthly training program.

\section{Recommendation \#4: Phase in a mandatory wellness and fitness program to benefit all fire fighters.}

Discussion: Volunteer and career fire fighters have high rates of modifiable risk factors for cardiovascular disease, including overweight/obesity, low fitness, hypertension, and unhealthy cholesterol levels [Poston et al. 2011; Scanlon and Ablah 2008; Soteriades et al. 2011]. Another hazard for fire fighters who are not physically fit is a greater likelihood of being injured on duty [Poston et al. 2013]. According to NFPA 1583, Standard on Health-Related Fitness Programs for Fire Fighters, the aim of a wellness-fitness program is to assist fire fighters to build and maintain a level of health and fitness so that they can better perform their duties and reduce the risk of injury, illness, and premature death [NFPA 2015]. Fire service health promotion programs have been shown to reduce cardiovascular disease risk factors and improve fitness levels, with mandatory programs showing the greatest benefit [Blevins et al. 2006; Dempsey et al. 2002; Womack et al. 2005].

The fire department does not have a wellness-fitness program and no exercise equipment is available in the fire stations. NIOSH recommends the department phase in a mandatory wellness-fitness program to help reduce risk factors for cardiovascular disease. Given the department's structure and budget limitations, tools that may be helpful for starting a program include the Heart-Healthy Firefighter Resources Guide [NVFC 2011] and the Health and Wellness Guide for the Volunteer Fire and Emergency Services [USFA 2009].

Additional guidance for fire department programs to reduce risk factors and improve cardiovascular capacity is found in the Fire Service Joint Labor Management Wellness/Fitness Initiative [IAFF and IAFC 2008].

Recommendation \#5: Provide fire fighters with medical clearance to wear SCBA as part of the fire department's medical evaluation program.

Discussion: The Occupational Safety and Health Administration (OSHA) Revised Respiratory Protection Standard requires employers to provide medical evaluations and clearance for employees using respiratory protection [29 CFR 1910.134]. These clearance evaluations are required for private industry employees and for public employees in states that operate OSHA-approved state plans. 


\section{8-Year-Old Captain Suffers a Heart Attack at a Medical Call and Dies 4 Days Later-Nebraska}

Because Nebraska does not operate a state OSHA plan [OSHA 2016], the fire department is not required to provide medical evaluations for employees using respirators. However, we recommend voluntary compliance with the OSHA standard to benefit fire fighter health and safety.

\section{References}

ADA [no date]. eAG/A1C conversion calculator. Arlington, VA: American Diabetes Association, https://professional.diabetes.org/diapro/glucose_calc.

ADA [2017]. Standards of medical care in diabetes-2017. Abridged for primary care providers. Clin Diabetes 35(1):5-26, https://dx.doi.org/10.2337/cd16-0067.

AHA [2015]. Ejection fraction heart failure measurement. Dallas, TX: American Heart Association, http://www.heart.org/HEARTORG/Conditions/HeartFailure/DiagnosingHeartFailure/EjectionFraction-Heart-Failure-Measurement_UCM_306339_Article.jsp\#.WOQUfcJU270.

AHA [2016a]. Understand your risk of heart attack. Dallas, TX: American Heart Association, http://www.heart.org/HEARTORG/Conditions/HeartAttack/UnderstandYourRiskofHeartAttack/Under stand-Your-Risk-of-Heart-Attack_UCM_002040_Article.jsp.

Ainsworth BE, Haskell WL, Herrmann SD, Meckes N, Bassett DR Jr, Tudor-Locke C, Greer JL, Vezina J, Whitt-Glover MC, Leon AS [2011]. Compendium of physical activities: a second update of codes and MET values. Med Sci Sports Exerc 43(8):1575-1581, https://asu.pure.elsevier.com/en/publications/2011-compendium-of-physical-activities-a-secondupdate-of-codes-a.

Albert CM, Mittleman MA, Chae CU, Lee IM, Hennekens CH, Manson JE [2000]. Triggering of sudden death from cardiac causes by vigorous exertion. N Engl J Med 343(19):1355-1361, http:dx.doi.org/10.1056/NEJM200011093431902.

Blevins JS, Bounds R, Armstrong E, Coast JR [2006]. Health and fitness programming for fire fighters: does it produce results? Med Sci Sports Exerc 38(5):S454.

CFR. Code of Federal Regulations. Washington, DC: U.S. Government Printing Office, Office of the Federal Register, https://www.gpo.gov/.

Dempsey WL, Stevens SR, Snell CR [2002]. Changes in physical performance and medical measures following a mandatory firefighter wellness program. Med Sci Sports Exerc 34(5):S258.

Gledhill N, Jamnik VK [1992]. Characterization of the physical demands of firefighting. Can J Sport Sci 17(3):207-213, PMID: 1325260.

Hong YM [2010]. Atherosclerotic cardiovascular disease beginning in childhood. Korean Circ J 40(1):1-9, http://dx.doi.org/10.4070/kcj.2010.40.1.1.

IAFC [2013]. A fire department's guide to implementing NFPA 1582. Fairfax, VA: International Association of Fire Chiefs, https://www.iafc.org/topics-and-tools/resources/resource/fire-departmentsguide-to-implementing-nfpa-1582. 


\section{8-Year-Old Captain Suffers a Heart Attack at a Medical Call and Dies 4 Days Later-Nebraska}

IAFC [2016]. Healthcare provider’s guide to firefighter physicals. Fairfax, VA: International Association of Fire Chiefs, http://www.fstaresearch.org/resource/?FstarId=11591.

IAFF, IAFC [2008]. The fire service joint labor management wellness/fitness initiative. 3rd ed. Washington, DC: International Association of Fire Fighters, International Association of Fire Chiefs.

Jneid H, Alam M, Virani SS, Bozkurt B [2013]. Redefining myocardial infarction: what is new in the ESC/ACCF/AHA/WHF third universal definition of myocardial infarction? Methodist Debakey Cardiovasc J 9(3):169-172, PMID: 24066201.

Johnson B, Francis J [2014]. Stress and cardiac arrhythmias. Indian Pacing Electrophysiol J 14(5):230232, PMID: 25408562.

Kales SN, Soteriades ES, Christoudias SG, Christiani DC [2003]. Firefighters and on-duty deaths from coronary heart disease: a case control study. Environ health: a global access science source 2:14, http://www.ehjournal.net/content/2/1/14.

Kales SN, Soteriades ES, Christophi CA, Christiani DC [2007]. Emergency duties and deaths from heart disease among fire fighters in the United States. N Engl J Med 356(12):1207-1215, http://dx.doi.org/10.1056/NEJMoa060357.

Lang RM, Badano LP, Mor-Avi V, Afilalo J, Armstrong A, Ernande L, Flachskampf FA, Foster E, Goldstein SA, Kuznetsova T, Lancellotti P, Muraru D, Picard MH, Rietzschel ER, Rudski L, Spencer KT, Tsang W, Voigt JU [2015]. Recommendations for cardiac chamber quantification by echocardiography in adults: an update from the American Society of Echocardiography and the European Association of Cardiovascular Imaging. Eur Heart J Cardiovasc Imaging 16(3):233-270, http://dx.doi.org/10.1093/ehjci/jev014

Levy D, Garrison RJ, Savage DD, Kannel WB, Castelli WP [1990]. Prognostic implications of echocardiographically determined left ventricular mass in the Framingham Heart Study. N Engl J Med 323(24):1706-1707, PMID: 2139921.

Libby P [2002]. Atherosclerosis: the new view. Sci Am 286(5):46-55, PMID: 11951331.

Libby P [2015]. The pathogenesis, prevention, and treatment of atherosclerosis. In: Kasper DL, Hauser SL, Jameson JL, Fauci AS, Longo DL, Loscalzo J, eds. Harrison’s principles of internal medicine. 19th ed. New York: McGraw-Hill.

Lip GYH, Coca A, Kahan T, Boriani G, Manolis AS, Olsen MH, Oto A, Potpara TS, Steffel J, Marín F, de Oliveira Figueiredo MJ, de Simone G, Tzou WS, Chiang CE, Williams B [2017]. Hypertension and cardiac arrhythmias: executive summary of a consensus document from the European Heart Rhythm Association (EHRA) and ESC Council on Hypertension, endorsed by the Heart Rhythm Society (HRS), Asia-Pacific Heart Rhythm Society (APHRS) and Sociedad Latinoamericana de Estimulación Cardíaca y Electrofisiología (SOLEACE). Eur Heart J Cardiovasc Pharmacother, http:/dx.doi.org/10.1093/ehjcvp/pvx019.

Mittleman MA, Siscovick DS [1996]. Physical exertion as a trigger of myocardial infarction and sudden cardiac death. Cardiol Clin 14(2):263-270, PMID: 8724558. 


\section{8-Year-Old Captain Suffers a Heart Attack at a Medical Call and Dies 4 Days Later-Nebraska}

Myerburg RJ, Castellanos A [2015]. Cardiovascular collapse, cardiac arrest, and sudden cardiac death. In: Kasper DL, Hauser SL, Jameson JL, Fauci AS, Longo DL, Loscalzo J, eds. Harrison's principles of internal medicine. 19th ed. New York: McGraw-Hill.

Nathan DM, Kuenen J, Borg R, Zheng H, Schoenfeld D, Heine RJ [2008]. Translating the A1C assay into estimated average glucose values. Diabetes Care 31(8):1473-1478, http://dx.doi.org/10.2337/dc08$\underline{0545}$

NFPA [2013a]. Standard on comprehensive occupational medical program for fire departments. Quincy, MA: National Fire Protection Association. NFPA 1582.

NFPA [2013b]. Standard on fire department occupational safety and health program. Quincy, MA: National Fire Protection Association. NFPA 1500.

NFPA [2015]. Standard on health-related fitness programs for fire fighters. Quincy, MA: National Fire Protection Association. NFPA 1583.

NHLBI [2005]. High blood cholesterol: what you need to know. Bethesda, MD: U.S. Department of Health and Human Services, National Institutes of Health, National Heart, Lung, and Blood Institute, https://www.nhlbi.nih.gov/health/resources/heart/heart-cholesterol-hbc-what-html

NHLBI [2015]. Description of high blood pressure. Bethesda, MD: U.S. Department of Health and Human Services, National Heart, Lung, and Blood Institute, https://www.nhlbi.nih.gov/health/healthtopics/topics/hbp.

NHLBI [2016]. Who is at risk for coronary artery disease? Bethesda, MD: U.S. Department of Health and Human Services, National Heart, Lung, and Blood Institute, http://www.nhlbi.nih.gov/health/health-topics/topics/cad/atrisk.html.

NIOSH [2007]. NIOSH alert: preventing fire fighter fatalities due to heart attacks and other sudden cardiovascular events. Cincinnati, OH: U.S. Department of Health and Human Services, Centers for Disease Control and Prevention, National Institute for Occupational Safety and Health, DHHS (NIOSH) Publication No. 2007-133, http://www.cdc.gov/niosh/docs/2007-133/

NVFC [2011]. Heart-Healthy Firefighter Resources Guide. 2nd ed. Greenbelt, MD: National Volunteer Fire Council, http://www.healthy-firefighter.org/start-a-program.

NVFC [2016]. NVFC position on firefighter physicals. Greenbelt, MD: National Volunteer Fire Council, http://www.nvfc.org/wp-content/uploads/2016/09/NVFC-Position-on-FirefighterPhysicals.pdf.

OSHA [2016]. State occupational safety and health plans. Washington, DC: Occupational Safety and Health Administration, http://www.osha.gov/dcsp/osp/index.html.

Poston WS, Haddock CK, Jahnke SA, Jitnarin N, Day RS [2013]. An examination of the benefits of health promotion programs for the national fire service. BMC Pub Health 13(1):805-819, http://dx.doi.org/10.1186/1471-2458-13-805. 


\section{8-Year-Old Captain Suffers a Heart Attack at a Medical Call and Dies 4 Days Later-Nebraska}

Poston WS, Haddock CK, Jahnke SA, Jitnarin N, Tuley BC, Kales SN [2011]. The prevalence of overweight, obesity, and substandard fitness in a population-based firefighter cohort. J Occup Environ Med 53(3):266-273, http://dx.doi.org/10.1097/JOM.0b013e31820af362.

Scanlon P, Ablah E [2008]. Self-reported cardiac risks and interest in risk modification among volunteer firefighters: a survey-based study. J Am Osteopath Assoc 108(12):694-698, PMID: 19075033.

Siegel RJ [1997]. Myocardial hypertrophy. In: Bloom S, ed. Diagnostic criteria for cardiovascular pathology acquired diseases. Philadelphia, PA: Lippencott-Raven.

Soteriades ES, Hauser R, Kawachi I, Liarokapis D, Christiani DC, Kales SN [2005]. Obesity and cardiovascular disease risk factors in firefighters: a prospective cohort study. Obes Res 13(10):17561763, http://dx.doi.org/10.1038/oby.2005.214.

Stary HC. Evolution and progression of atherosclerotic lesions in coronary arteries of children and young adults [1989]. Arteriosclerosis 9(1 Suppl):I19-32, PMID: 2912430.

Thygesen K, Alpert JS, Jaffe AS, Simoons ML, Chaitman BR, White HD; Joint ESC/ACCF/AHA/WHF Task Force for the Universal Definition of Myocardial Infarction, Katus HA, Lindahl B, Morrow DA, Clemmensen PM, Johanson P, Hod H, Underwood R, Bax JJ, Bonow RO, Pinto F, Gibbons RJ, Fox KA, Atar D, Newby LK, Galvani M, Hamm CW, Uretsky BF, Steg PG, Wijns W, Bassand JP, Menasché P, Ravkilde J, Ohman EM, Antman EM, Wallentin LC, Armstrong PW, Simoons ML, Januzzi JL, Nieminen MS, Gheorghiade M, Filippatos G, Luepker RV, Fortmann SP, Rosamond WD, Levy D, Wood D, Smith SC, Hu D, Lopez-Sendon JL, Robertson RM, Weaver D, Tendera M, Bove AA, Parkhomenko AN, Vasilieva EJ, Mendis S [2012]. Third universal definition of myocardial infarction. Circulation 126(16):2020-2035, http://dx.doi.org/10.1161/CIR.0b013e31826e1058.

Tin LL, Beevers DG, Lip GY [2002]. Hypertension, left ventricular hypertrophy, and sudden death Curr Cardiol Rep 4(6):449-454, PMID: 12379162.

USFA [2009]. Health and wellness guide for the volunteer fire and emergency services. Emmitsburg, MD: Federal Emergency Management Agency; United States Fire Administration. Publication No. FA-321, https://www.usfa.fema.gov/downloads/pdf/publications/fa_321.pdf.

Willich SN, Lewis M, Lowel H, Arntz HR, Schubert F, Schroder R [1993]. Physical exertion as a trigger of acute myocardial infarction. N Engl J Med 329(23):1684-1690, PMID: 8232457.

Womack JW, Humbarger CD, Green JS, Crouse SF [2005]. Coronary artery disease risk factors in firefighters: effectiveness of a one-year voluntary health and wellness program. Med Sci Sports Exerc 37(5):S385.

Yang J, Teehan D, Farioli A, Baur DM, Smith D, Kales SN [2013]. Sudden cardiac death among firefighters $\leq 45$ years of age in the United States. Am J Cardiol 112(12):1962-1967, http://dx.doi.org/10.1016/j.amjcard.2013.08.029.

\section{Investigator Information}




\section{8-Year-Old Captain Suffers a Heart Attack at a Medical Call and Dies 4 Days Later-Nebraska}

This incident was investigated by the NIOSH Fire Fighter Fatality Investigation and Prevention Program, Cardiac and Medical Line-of-Duty Deaths (LODD) Investigations Team, in Cincinnati, Ohio. Mr. Tommy Baldwin, MS, led the investigation and co-authored the report. Mr. Baldwin is a Safety and Occupational Health Specialist, an International Fire Service Accreditation Congress (IFSAC) Certified Fire Officer I, a National Association of Fire Investigators (NAFI) Certified Fire and Explosion Investigator, and a former Fire Chief and Emergency Medical Technician. Wendi Dick, MD, MSPH, provided medical consultation and co-authored the report. Dr. Dick is Lead for the Cardiac and Medical LODD Investigations Team in Cincinnati.

\section{Disclaimer}

Mention of any company or product does not constitute endorsement by the National Institute for Occupational Safety and Health (NIOSH). In addition, citations to websites external to NIOSH do not constitute NIOSH endorsement of the sponsoring organizations or their programs or products.

Furthermore, NIOSH is not responsible for the content of these websites. All web addresses referenced in this document were accessible as of the publication date. 